\title{
Patterns and Outcomes of Cutaneous Adverse Drug Reactions in a Hospital Based Study
}

\author{
Paudel U1', Parajuli S², Pokhrel DB ${ }^{3}$ \\ ${ }^{1,2}$ Assistant Professor, ${ }^{3}$ Professor, Department of Dermatology, Maharajgunj Medical Campus, Maharajgunj.
}

\author{
Address for correspondence \\ Dr. Upama Paudel \\ Phone: 9841256983 \\ E-mail : upama_ups@yahoo.com
}

\begin{abstract}
Introduction : Drug reactions are one of the common reasons for admission in the Dermatological beds. Data on the culprit drugs and patterns of reaction are very scarce in Nepal.

Objective: To determine the patterns of drug reactions admitted in Tribhuwan University (TU) Teaching hospital, the causes of drug reactions, duration of hospital stay, duration of steroid use and the outcome of the treatment.

Material and Methods: This was a retrospective study done in TU Teaching Hospital. The admissions and discharge record of admitted patients from $15^{\text {th }}$ April 2008 to $14^{\text {th }}$ April 2012 were analyzed for the variables mentioned above.

Results: There were 61 new patients of drug reactions; however only files of 42 patients could be studied.The mean age of the patients was 32.26 / 15.26 with male to female ratio of 1.8:1. Stevens Johnson's syndrome (35.7\%) was the commonest cause of admission followed by drug induced erythroderma (16.7\%) and toxic epidermal necrolysis (11.9\%). Carbamazepine, Phenytoin and allopurinol were the most common drugs for the reactions. The median time for the appearance of the lesions was 20.07 days. The median duration of hospital stay was 7 days. Steroids were used for initial treatment for around $4.9+/-1.7$ days. $83.3 \%$ of the patients improved while $11.9 \%$ succumbed despite optimal management.

Conclusion: Severe drug reactions were the common reasons for admissions in our hospital. Anti-epileptics were the leading cause for the reactions. Steroids were used for initial period and rapidly tapered off in short duration. Overall, the outcomes of the treatment were good.
\end{abstract}

Key words: cutaneous drug reactions; steroids; steven-johnson syndrome; toxic epidermal necrolysis

\section{Introduction}

Drugs can cure, suppress or prevent a disease and are usually beneficial to humans.

However, they can also produce undesirable/harmful effects, which are known as adverse drug reactions (ADRs). Cutaneous adverse drug reactions (CADRs) can be defined as noxious, unintended morphological skin changes with or without systemic involvement, developed after local or systemic administration of drugs in dosages commonly used for prevention, diagnosis or treatment of disease or modification of physiological functions, in accordance with the World Health Organization's general definition of adverse drug reactions (ADRs). ${ }^{1}$

Cutaneous ADRs can be caused by a wide variety of agents. The spectrum of Cutaneous ADRs ranges from a transient maculopapular rash to fatal reactions like SJS, TEN and DRESS. ${ }^{2,3}$ They account for about $5 \%$ of all hospital admissions in the UK. ${ }^{4}$ The incidence of cutaneous ADRs among inpatients in developed countries ranges from $1-3 \%$ whereas in India it is $2-5 \%{ }^{5}$, however, the data from our country is limited.

ADRs are reportedly responsible for up to $7 \%$ of hospital admissions, and cutaneous ADRs alone contribute to $2-3 \%$ of the overall hospital admissions. ${ }^{6,7}$ Up to $30-45 \%$ of the ADRs are reportedly cutaneous in nature, $2 \%$ of which may be severe and few may even end in fatalities. ${ }^{8,9}$ Incidence of fatal cutaneous ADRs in the US is $0.32 \% .^{10}$

The most common CADR is morbilliform exanthema $(\mathrm{ME})$, but it is also the least specific manifestation. 
Other potentially severe forms are more specific, but they are less frequently encountered. ${ }^{11}$

The aim of this study is to report the various reaction patterns of the severe cutaneous adverse drug reactions and their putative drugs, as well as the outcome among the patients who were managed in a tertiary hospital of Nepal from $15^{\text {th }}$ April 2008 to $14^{\text {th }}$ April 2012.

\section{Material and Methods}

In this mono centric study, a retrospective analysis of all hospital records of severe cutaneous adverse drug reactions admitted in the dermatology ward of the TUTH from $15^{\text {th }}$ April 2008 to $14^{\text {th }}$ April 2012 was conducted. The age and sex of the patient, the offending drug, the time interval between the drug intake and the eruption, duration of hospital stay, outcome and sequel were recorded. Based on morphology, distribution of the lesions, and clinical examination of the CADR, toxic epidermal necrolysis (TEN) and Stevens Johnson syndrome (SJS); Erythroderma (ED); and drug hypersensitivity syndrome (DHS) were distinguished.

\section{Results}

There were a total of 283 new admissions in the Dermatology ward, out of which 61 patients (21.6\%) were having drug reactions, in a four years period, but only 42 files could be retrieved. There were $27(64.3 \%)$ males and $15(35.7 \%)$ females. The mean age of the patients was $32.26+/-15.26$ (ranging from 11 to 75 years). The commonest age group to be affected by drug reactions was $26-35$ years. (Table 1 ).

Table 1: Age group of patients admitted with CADRs

\begin{tabular}{|c|c|}
\hline Age Group & Number (\%) \\
\hline$<14$ years & $4(9.5 \%)$ \\
\hline $15-25$ years & $11(26.2 \%)$ \\
\hline $26-35$ years & $12(28.6 \%)$ \\
\hline $36-45$ years & $8(19 \%)$ \\
\hline $46-55$ years & $3(7.1 \%)$ \\
\hline $56-65$ years & $2(4.8 \%)$ \\
\hline$>65$ years & $2(4.8 \%)$ \\
\hline Total & $\mathbf{4 2 ( 1 0 0 \% )}$ \\
\hline
\end{tabular}

Twenty four (57.1\%) patients had history of intake of single medication and 18 (42.9\%) had taken multiple medications. Among the multiple drugs, antibiotics with NSAIDs were common combinations.

Maximum number of cases were diagnosed as SJS (15 cases) followed by 7 cases each of erythroderma and extensive exanthematous drug eruption. There were 5 cases of TEN, 3 cases each of drug hypersensitivity syndrome and SJS-TEN overlap; 1 case each of FDE and EM (Table 2).

Table 2: Types of CADR

\begin{tabular}{|c|c|}
\hline Diagnosis & Number(\%) \\
\hline SJS & $15(35.7 \%)$ \\
\hline TEN & $5(11.8 \%)$ \\
\hline SJS-TEN & $3(7.1 \%)$ \\
\hline Erythroderma & $7(16.7 \%)$ \\
\hline Exanthematous drug eruption & $7(16.7 \%)$ \\
\hline Drug hypersensitivity syndrome & $3(7.2 \%)$ \\
\hline Erythema multiforme & $1(2.4 \%)$ \\
\hline Fixed drug eruption & $1(2.4 \%)$ \\
\hline Total & 42 (100\%) \\
\hline
\end{tabular}

The median time for appearance of lesions after medication was 20.07 days.(ranging from 2 days to 90 days) (Table 3).

Table : 3 Latency period

\begin{tabular}{|c|c|}
\hline Time interval & Number(\%) \\
\hline$<7$ days & $15(35.7 \%)$ \\
\hline 7-14 days & $8(19 \%)$ \\
\hline $15-21$ days & $4(9.5 \%)$ \\
\hline$>21$ days & $15(35.7 \%)$ \\
\hline Total & $\mathbf{4 2 ( 1 0 0 \% )}$ \\
\hline
\end{tabular}

Carbamazepine and phenytion were the two most common culprits for 8 and 7 cases of CADRs respectively. Various putative drugs and the clinical reaction patterns caused by them are depicted in Table 4 .

Out of 42 cases, 26 patients were managed with tapering doses of IV corticosteroids, i.e. hydrocortisone, rest were managed with supportive and symptomatic therapy. Patients receiving corticosteroid therapy were all 5 cases of TEN, 3 cases of SJS-TEN, 13 out of 15 cases of SJS, 2 out of 7cases of erythroderma, 2 cases of exanthematous drug eruption and a case of EM. The average duration of steroid therapy was 4.88 days (SD 1.68), ranging from 2 days to 9 days.

The median duration of hospital stay was 7 days (minimum of 3 days to a maximum of 51 days). Despite of optimal management,11.9\% $(n=5)$ succumbed; however, $83.3 \%$ ( $n=35)$ cases improved. One case was referred to other speciality for management of comorbidities and one case left against medical advice. Cases who succumbed were 3 cases of TEN ( 2 caused by unknown medication and 1 caused by allopurinol), 1 case of erythroderma caused by phenytion and 1 case of DRESS caused by leflunomide. 
Paudel $U$ et al.

Table 4: Various putative drugs and their associated clinical reaction pattern

\begin{tabular}{|c|c|c|c|c|c|c|c|c|c|}
\hline \multirow[b]{2}{*}{ Drug } & \multicolumn{8}{|c|}{ Diagnosis } & \multirow[t]{2}{*}{ Total } \\
\hline & SJS & TEN & SJS-TEN & Erythroderma & $\begin{array}{c}\text { Exanthematous } \\
\text { Drug Eruption }\end{array}$ & DHS & EM & FDE & \\
\hline Carbamazepine & 4 & 1 & 2 & & 1 & & & & $8(19 \%)$ \\
\hline Phenytoin & 3 & & & 3 & 1 & & & & $7(16.7 \%)$ \\
\hline Allopurinol & & 1 & 1 & 1 & 1 & & & & $4(9.5 \%)$ \\
\hline Cotrimoxazole & & & & & 2 & & 1 & & $3(7.1 \%)$ \\
\hline Ciprofloxacin & 2 & & & 1 & & & & & $3(7.1 \%)$ \\
\hline Ceftriaxone & 1 & & & 1 & & & & & $2(4.8 \%)$ \\
\hline Lamotrigine & & 1 & & & 1 & & & & $2(4.8 \%)$ \\
\hline Amoxycillin & 1 & & & & & & & & $1(2.4 \%)$ \\
\hline ATT & 1 & & & & & & & & $1(2.4 \%)$ \\
\hline Cefixime & & & & & & & & 1 & $1(2.4 \%)$ \\
\hline Paracetamol & 1 & & & & & & & & $1(2.4 \%)$ \\
\hline Sulfasalazine & & & & & & 1 & & & $1(2.4 \%)$ \\
\hline Leflunomide & & & & & & 1 & & & $1(2.4 \%)$ \\
\hline Dapsone & & & & & & 1 & & & $1(2.4 \%)$ \\
\hline Unknown & 2 & 2 & & 1 & 1 & & & & $6(14.2 \%)$ \\
\hline Total & 15 & 5 & 3 & 7 & 7 & 3 & 1 & 1 & $42(100 \%)$ \\
\hline
\end{tabular}

\section{Discussion}

Adverse drug reactions may affect any organ, and the skin is the commonly involved organ. CADRs are usually benign. Severe forms are rare, with an estimated proportion of $2 \% .{ }^{12,13}$ The course can be fatal in 0.2 to $29.3 \%$ of cases requiring hospitalization when a severe evolution is predicted. ${ }^{12}$ The recognition of the dermatological reaction patterns and the exclusion of differentials are of primary importance for which history and clinical examination form the cornerstone of diagnosis. ${ }^{10}$ These various reaction patterns have different temporal relationships between the time of administration of the medication and the onset of dermatoses, although this latency may be shortened in the event of a re-exposure. Retrospective studies of drug eruptions have been reported by many countries and regions but retrospective study of inpatients with CADRs in Nepal has not previously been reported, to our knowledge.

Comparing the incidence of CADRs by gender, we found our inference to be conflicting with some studies reporting a female preponderance ${ }^{14,15,16}$ and was in line with other studies with male preponderance. $3,17,18$ This study showed male preponderance with male female ratio of 1.8 . Our study revealed $54.8 \%$ cases of CADRs being in age group of 15 to 35 years and similar age groups were affected by CADRs in few other studies. 3,14,17,18 Literatures suggested maculopapular eruptions as the most frequent reaction pattern ${ }^{3,15,19,20}$ while according to our study
SJS $(35.7 \%)$ was the most common CADR, while maculopapular eruptions and erythroderma were second highest reactions with $16.7 \%$ each. The reason behind this may be the management of less severe exanthematous drug reactions in outpatient basis. In our study the latency was 2 - 90 days with an average of 20.07days, this was similar to the latency of 3 to 60 days in Tunisia. ${ }^{15}$ However, one study revealed the latency for SIS/TEN to be few hours to one week ${ }^{3}$ where as in another study $71.3 \%$ of CADR cases had a latency of less than a week. ${ }^{17}$ It was $2-14$ days in $80 \%$ cases in a North Indian study. ${ }^{21}$ Almost $36 \%$ cases had latency of less than a week in our study as well, this reduction in latency may be due to repeated exposure to medications. Common drugs associated with CADR were anticonvulsants namely carbamazepine $(n=8)$ and phenytoin $(n=7)$ followed by different antibiotics and unknown medications. This result was similar to a Tunisian study but in contrast to many other studies where antibiotics were the common culprits followed by anticonvulsants. ${ }^{5,10,12,14,18,20}$ However unknown medication made second largest group in a study ${ }^{17}$ and it was $14.4 \%(n=6)$ in our study. Carbamazepine accounted for $24 \%$ SJS/TEN in a study from Malaysia. ${ }^{19}$ Recently, many studies on allele associations with cutaneous ADR induced by aromatic amine anticonvulsants have been reported in Asian and European populations. Current studies indicate that HLAB*1502 is a marker for carbamazepine-induced SJS/TEN in Southeast Asian populations, where the prevalence of HLA-B*1502 is relatively high. ${ }^{22}$ 
The role of corticosteroids in the treatment of SJS/TEN is controversial. Earlier studies suggested increased morbidity and mortality. ${ }^{23,24} \mathrm{~A}$ retrospective analysis of 289 patients from the Euro SCAR study found no benefit from corticosteroids or IVIg compared to supportive care alone. ${ }^{25}$ There are, however, few studies suggesting benefits in administering high-dose corticosteroids early in the course of disease..$^{26,27,28}$ Possible explanation for this contradictory evidence may be due to the unfavourable outcomes from the use of corticosteroids resulting from inadequate doses, a delay in the initiation of treatment and the increased risk of mortality from sepsis from prolonged courses of therapy. However, in our study, the use of systemic corticosteroids with rapid tapering has given favorable results with median duration of hospital stay being 7 days, (minimum of 3 days to a maximum of 51 days) which was similar to a Chinese study ${ }^{16}$ but slightly higher than that of Singapore ${ }^{10}$ where it was 2-24 days (average 9days). Despite optimal management, there was $11.9 \%$ mortality; cases who succumbed were 3 cases of TEN ( 2 caused by unknown medication and 1 caused by allopurinol) 1 case of erythroderma caused by phenytion, 1 case of DRESS caused by leflunomide. In general, the mortality rate in Stevens-Johnson syndrome (SJS) and toxic epidermal necrolysis (TEN)

\section{References}

1. Gardner P, Cluff LE. The epidemiology of adverse drug reactions. A review and perspective. Johns Hopkins Med J 1970; 126: 77-87.

2. Sharma VK, Sethuraman G. Adverse cutaneous reactions to drugs: an overview. J Postgrad Med 1996; 42: 15-22.

3. Sharma VK, Sethuraman G, Kumar B. Cutaneous adverse drug reactions: Clinical pattern and causative agents- $A$ six-year series from Chandigarh, India. J Postgrad Med 2001; 47: 959. https://doi.org/10.1136/bmj.316.7140.1295

4. Pirmohamed $M$, Breckenridge $A M$, Kitteringha NR, Park BK. Adverse drug reactions. BMJ 1998; 316: 1295-1298. https://doi.org/10.4103/02537613.28212

5. Chatterjee S, Ghosh AP, Barbhuiya J, Dey SK. Adverse cutaneous drug reactions: $A$ one year survey at a dermatology outpatient clinic of a tertiary care hospital. Indian J Pharmacol 2006; 38: 429-431

6. Wiffen P, Gill M, Edwards J, Moore A. Adverse drug reactions in hospital patients. A systematic is high; approximately $5 \%$ for SJS and $30 \%$ for TEN. ${ }^{29}$ In one of the studies, 4 out of 7 cases of TEN expired, which comprised $40 \%$ of all ADR related mortalities. ${ }^{20}$ In another study, 5 out of 12 cases of TEN and 2 out of 3 cases of erythroderma succumbed. ${ }^{15}$ Overall mortality of CADR in another study was $5.1 \%$, which consisted of 2 mortalities of SJS/TEN and 3 of TEN. ${ }^{10}$ Mortality rate was $15.6 \%$ among all cases; $9 \%$ in SJS and $26.7 \%$ in TEN in another study. ${ }^{30}$

\section{Conclusion}

Most of the results obtained in our study are comparable to what are reported in the literatures. The role of corticosteroids is currently under revision. Some earlier studies have shown their lack of efficacy or increased mortality in their use but the use of high doses early in the course of the disease may actually reduce morbidity and mortality, which has been shown in our study too.

A retrospective study has several limitations. Our data may not include all the patients with CADRs because some of them may not have been admitted to our hospital, in addition all data could not be retrieved due to poor record keeping.

review of the prospective and retrospective studies. Bandolier Extra 2002; 2: 1-16. https:// doi.org/10.1067/mai.2000.106156

7. Gruchalla R. Understanding drug allergies. J Allergy Clin Immunol 2000; 105: 637-44. https:// doi.org/10.1046/j.1365-2125.1999.00096.x

8. Naldi L, Conforti A, Venegoni M, Troncon MG, Caputi A, Ghiotto E, et al. Cutaneous reactions to drugs. An analysis of spontaneous reports in four Italian regions. Br J Clin Pharmacol 1999; 48: 839-46.

9. Ajayi FO, Sun H, Perry J. Adverse drug reactions: A review of relevant factors. J Clin Pharmacol 2000; 40: 1093-101.

10. Lee HY, Tay LK, Thirumoorty T, Pang SM. Cutaneous adverse drug reactions in hospitalised patients Singapore Med J 2010; 51(10) : 767

11. Roujeau JC, Stern RS. Severe adverse cutaneous reactions to drugs. N Eng J Med 1994; 331: 1272-85. https://doi.org/10.1056/ NEJM199411103311906

12. Hernandez-Salazar A, Ponce-de-Leon Rosales S, Rangel-Frausto S. Epidemio logy of adverse 
cutaneous drug reactions: a prospective study in hospitalized patients. Arch Med Res 2006; 37: 899-902. https://doi.org/10.1016/j. arcmed.2006.03.010

13. Wolf $\mathrm{R}$, Orion $\mathrm{E}$, Marcos B. Life-threatening acute adverse cutaneous drug reactions. Clin Dermatol 2005; 23: 171-181. https://doi. org/10.1016/j.clindermatol.2004.06.012

14. Pudukadan D, Thappa DM. Adverse cutaneous drug reactions: Clinical pattern and causative agents in a tertiary care centre in South India. Indian J Dermatol Venereol Leprol 2004; 70: 204.

15. Zaraa I, Jones M, Trojjet S, Rouhou RC, Euch DE, Mokni M, et al. Severe adverse cutaneous drug eruptions: epidemiological and clinical features. International Journal of Dermatology 2011; 50: 877-880. https://doi.org/10.1111/ j.1365-4632.2010.04785.x

16. Huang $H Y$, Luo $X Q$, Chan LS, Cao ZH, Sun XF, $\mathrm{Xu} \mathrm{JH}$. Cutaneous adverse drug reactions in a hospital-based Chinese population. Clinical and Experimental Dermatology 2010; 36: 135-141. https://doi.org/10.1111/j.13652230.2010.03922.x

17. Shah SP, Desai MK, Dikshit RK. Analysis of Cutaneous Adverse Drug Reactions at a Tertiary Care Hospital - a Prospective Study. Tropical Journal of Pharmaceutical Research August 2011; 10 (4): 517-522. https://doi.org/10.4314/ tjpr.v10i4.18

18. Raut A, Pawar A, Pankaj M, Srivastava P, Mishra A. Clinical pattern and severity of cutaneous adverse drug reactions. Int J Pharm Pharm Sci; 2013: 5, Suppl 2, 612-61.

19. Ding WY, Lee CK, Choon SE. Cutaneous adverse drug reactions seen in a tertiary hospital in Johor, Malaysia. Int J Dermatol. 2010; 49(7): 834-41. https://doi.org/10.1111/j.13654632.2010.04481.x

20. Jhaj R, Uppal R, Malhotra S, Bhargava VK. Cutaneous adverse reactions in in-patients in a tertiary care hospital. Indian J Dermatol Venereol Leprol 1999; 65: 14-7.

21. Nandha R, Gupta A, Hashmi A. Cutaneous adverse drug reactions in a tertiary care teaching hospital: A North Indian perspective. International journal of Applied and Basic medical research. $2011 ; 1(1): 50-53$. https:// doi.org/10.4103/2229-516X.81982

22. Aihara M. Pharmacogenetics of cutaneous adverse drug reactions. Journal of Dermatology 2011; 38: 246-254. https://doi.org/10.1111/ j.1346-8138.2010.01196.x

23. Rasmussen JE. Erythema multiforme in children. Response to treatment with systemic corticosteroids. Br. J. Dermatol. 1976; 95: 1816. https://doi.org/10.1111/j.1365-2133.1976. tb00824.x

24. Halebian PH, Corder VJ, Madden MR. Improved burn center survival of patients with toxic epidermal necrolysis managed without corticosteroids. Ann. Surg. 1986; 204: 503-12. https://doi.org/10.1097/00000658198611000-00001

25. Schneck J, Fagot JP, Sekula P. Effects of treatments on the mortality of StevensJohnson syndrome and toxic epidermal necrolysis: A retrospective study on patients included in the prospective EuroSCAR Study. J. Am. Acad. Dermatol. 2008; 58: 33-40. https:// doi.org/10.1016/j.jaad.2007.08.039

26. Kakourou T, Klontza D, Soteropoulou F. Corticosteroid treatment of erythema multiforme major (Stevens-Johnson syndrome) in children. Eur. J. Pediatr. 1997; 156: 0-3.

27. Kardaun SH, Jonkman MF. Dexamethasone pulse therapy for Stevens-Johnson syndrome/ toxic epidermal necrolysis. Acta Derm. Venereol. 2007; 87: 144-8. https://doi. org/10.2340/00015555-0214

28. Yamane Y, Aihara M, Tatewaki S. [Analysis of treatments and deceased cases of severe adverse drug reactions - analysis of 46 cases of Stevens-Johnson syndrome and toxic epidermal necrolysis]. Arerugi 2009; 58: 537-47.

29. Fernando SL. The management of toxic epidermal necrolysisaj Australasian Journal of Dermatology (2012); 53(3): 165-71. doi: 10.1111/j.1440-0960.2011.00862.x.

30. Barvaliya M, Sanmukhani J, Patel T. Druginduced Stevens-Johnson syndrome (SJS), toxic epidermal necrolysis (TEN), and SJS-TEN overlap: a multicentric retrospective study. J Postgrad Med 2011 ; 57(2) :115-9. https://doi. org/10.4103/0022-3859.81865 